Fuko, M. (2002) Intellektualy i vlast' : Izbrannye politicheskie stat' $i$, vystupleniia $i$ interv' iu: transl. from Fr. Moscow, Praksis. Vol. 1. 384 p. (In Russ.).

Habermas, Yu. (2001) Teoriia kommunikativnogo deistviia. St. Petersburg, Nauka Publ. 380 p. (In Russ.).

Kheveshi, M. A. (2001) Tolpa, massy, politika: Istoriko-filosofskii ocherk. Moscow, Institute of Philosophy RAS. 223 p. (In Russ.).

Chernigovskaia, T. Kak nauchit' mozg uchit'sia. Otkrytoe prostranstvo [online] Available at: http://otkrytoe-prostranstvo.ru/passed-lecture/tatyana-chernigovskaya-kak-nauchit-mozg-uchitsya/ (access date: 08.08.2017). (In Russ.).

Iulina, N. S. (2004) Golovolomki problemy soznaniia: kontseptsiia Deniela Denneta. Moscow, Canon+. 544 p. (In Russ.).

Pariser, E. (2012) The Filter Bubble. Penguin Books Ltd. 304 p.

Submission date: 25.08.2017.

Кожаринова Анна Ростиславовна - кандидат философских наук, доцент кафедры философии, культурологии и политологии Московского гуманитарного университета. Адрес: 111395 , Россия, г. Москва, ул. Юности, д. 5. Тел.: +7 (499) 374-55-11. Эл. адрес: anna_adv@inbox.ru

Kozharinova Anna Rostislavovna, Candidate of Philosophy, Associate Professor, Department of Philosophy, Culturology and Politology, Moscow University for the Humanities. Postal address: 5, Yunosti St., Moscow, Russian Federation 111395. Tel.: +7 (499) 374-55-11. E-mail: anna adv@inbox.ru

DOI10.17805/zpu.2017.4.3

\title{
Включенность в дополнительное профессиональное образование жителей европейских государств
}

\author{
В. А. ПРОХОДА
}

\author{
МОСКОВСКИЙ ГОСУДАРСТВЕННЫЙ УНИВЕРСИТЕТ ИМ. М. В. ЛОМОНОСОВА; \\ ФИНАНСОВЫЙ УНИВЕРСИТЕТ ПРИ ПРАВИТЕЛЬСТВЕ РОССИЙСКОЙ ФЕДЕРАЦИИ
}

В публикации анализируются результаты сравнительного межстранового социологического исследования «Европейское Социальное Исследование» (2014 г.). Выявлены масштабы включенности населения европейских стран в дополнительное профессиональное образование (ДПО). Европейские страны весьма дифференцированы по показателю охвата населения ДПО. В числе лидеров по масштабам включенности оказались Финляндия, Дания, Норвегия, Швеция, Швейцария, Германия, Нидерланды.

Констатируется наличие в современной России противоречия между декларируемой необходимостью развития системы дополнительного профессионального образования и крайне низкими по европейским меркам масштабами включенности населения в систему ДПО. Отмечается, что результаты по России в целом соотносятся с данными других социологических исследований. На основе сравнительного анализа данных 2010 и 2014 гг. констатируется, что масштабы включенности россиян в дополнительное профессиональное образование устойчивы во времени. Рассмотрены источники финансирования ДПО. В абсолютном большинстве европейских стран обучение населения в системе ДПО в основном оплачивает работодатель. Особенно сильно это проявляется в Швеции, Дании, Франции, Нидерландах, Норвегии. 
Отмечается, что в России население, охваченное дополнительным профессиональным образованием, гораздо чаще жителей абсолютного большинства других европейских государств самостоятельно финансирует получение ДПО. Делается вывод, что в России государство не смогло масштабно привлечь работодателей к финансированию программ ДПО. Выявлено, что масштабы включенности жителей европейских стран в дополнительное профессиональное образование связаны с уровнем благосостояния населения и уровнем экономического развития государства. В целом чем выше размер средней месячной заработной платы в стране, тем больший процент жителей констатирует включенность в дополнительное профессиональное образование.

Ключевые слова: дополнительное профессиональное образование; дополнительное образование; непрерывное образование; образование взрослых; образование в течение жизни; включенность в образование; население европейских стран; Европа

\section{ВВЕАЕНИЕ}

$\mathrm{O}$ сновополагающим принципом развития современных систем образования в европейских странах становится непрерывное образование на протяжении всей жизни. С его помощью жители европейских государств должны получить равные возможности адаптироваться к требованиям социально-экономических перемен и активно участвовать в формировании будущего Европы (Меморандум ... : Электронный ресурс). Аополнительное профессиональное образование (АПО) выступает в качестве одного из основных направлений и способов практической реализации непрерывного образования.

Система $А П О$ в европейских странах развивается в соответствии с многочисленными национальными и международными правовыми документами, в том числе Конвенцией о развитии человеческих ресурсов Международной организации труда (MOT), Копенгагенской декларацией и др. В России в соответствии с Федеральным законом от 29 декабря 2012 г. № 273 «Об образовании в Российской Федерации» дополнительное профессиональное образование определяется как вид образования, осуществляемый посредством реализации дополнительных профессиональных программ (программ повышения квалификации и программ профессиональной переподготовки), направленный на удовлетворение образовательных и профессиональных потребностей, профессиональное развитие человека, обеспечение соответствия его квалификации меняющимся условиям профессиональной деятельности и социальной среды (Федеральный закон ... , 2012: Электронный ресурс). При этом подразумевается формальная форма организации получения дополнительного образования, завершающаяся выдачей общепризнанного документа.

В то же время, рассматривая различные виды образовательной деятельности, исследователи приходят к выводу о том, что в современных условиях имеет место "смешение форм формального, информального и неформального обучения в дополнительном профессиональном образовании, что способствует его модернизации» (Серякова, Кравченко, 2016: 15). Констатируется, что в западноевропейских странах имеет место диверсификация видов, содержания, форм обучения и организации АПО, что является результатом деления на институциональные и внеинституциональные формы.

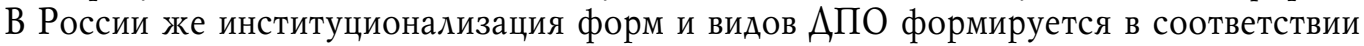
с законодательством в рамках единого подхода (Серякова, Кравченко, 2012: 35 ).

Процессы глобализации, формирование единого европейского образовательного пространства, унификация моделей образования, приверженность России Болонскому процессу и как следствие - согласование национальной системы образования с европейскими моделями предполагают возможность сравнения основных показате- 
лей отечественной и зарубежных систем дополнительного профессионального образования. Одним из ключевых показателей являются масштабы включенности населения в АПО.

Аанные официальной статистики, характеризующие масштабы включенности, отличаются большим разнообразием, что сопровождается различиями в подходах к официальной количественной оценке сектора АПО (Попова, 2011: 7). Использование автоматизированного сбора отчетных форм о функционировании системы дополнительного профессионального образования в России имеет большой потенциал, но пока не позволяет получить исчерпывающую статистическую информацию, характеризующую все сегменты и структуры АПО. Регулярно модернизируемая форма федерального статистического наблюдения № 1-ПК, в настоящее время именуемая «Сведения об обучении в организациях, осуществляющих образовательную деятельность по дополнительным профессиональным программам», собирается в основном на базе образовательных организаций (Аналитический ..., 2013; Аналитический ..., 2015: Электронный ресурс). В таких условиях выявление масштабов включенности населения в АПО даже в отдельно взятой стране сопряжено с рядом сложностей и подразумевает обращение к результатам эмпирических социологических исследований.

Международное сравнение масштабов охвата населения АПО сопряжено с еще большим количеством проблем, в том числе связанных с необходимостью гармонизации данных. Отметим, что в настоящее время ощущается определенный дефицит межстрановых сравнительных исследований, затрагивающих рассматриваемую проблематику. Последнее легко объяснимо, поскольку проведение подобных социологических опросов трудозатратно и сопряжено с существенными сложностями (Андреенкова, 2014).

Целью настоящей работы является выявление на основе результатов международного социологического исследования масштабов включенности в дополнительное профессиональное образование жителей европейских государств.

\section{МАТЕРИАИЫ И МЕТОАЫ}

Публикация базируется на результатах седьмой волны межстранового социологического исследования «Европейское Социальное Исследование» (European Social Survey, ESS)», проведенного в 2014 г. ESS - проект, в рамках которого с 2002 г. проводится многолетнее сравнительное изучение установок, взглядов, ценностей и поведения населения европейских стран (Россия участвует в ESS с 2006 г.). В 2014 г. опрос проводился в 22 странах среди населения в возрасте 15 лет и старше. Отметим, что Израиль географически расположен в Азии, однако не был исключен из анализа, поскольку в существенной степени интегрирован в европейское культурное пространство. В каждой стране было опрошено от 1224 (Словения) до 3045 (Германия) респондентов по национальной репрезентативной выборке. В России опрос проводился Институтом сравнительных социальных исследований (ЦЕССИ). Общее число опрошенных - 2445 человек. Метод сбора первичной социологической информации формализованное интервью. На международном уровне общее управление проектом осуществляли: The Centre for Comparative Social Surveys, City University London, UK; Scientific Advisory Board.

Обращение к вторичному анализу данных подразумевает использование существующей в рамках проекта операционализации основных понятий. B ESS для выявления масштабов включенности населения в дополнительное профессиональное образование респондентам задавался следующий вопрос: «B течение последних 12 меся- 
иев посещали ли Вы какие-либо курсы, лекчии, тренинги или занятия с иелью усовершенствования своих знаний или навьков, необходимых для работье? Предлагались два содержательных варианта ответа - «да» и «нет».

Распределение ответов на данный вопрос, на наш взгляд, в целом может характеризовать ситуацию с масштабами включенности населения европейских стран в АПО. Однако при этом возникают некоторые методологические сложности. Подразумевается использование широкого определения дополнительного профессионального образования, включающего в себя как формальное, так и неформальное обучение. Очевидно, что, например, посещение тренингов, проводимых успешным сотрудником на работе, может не сопровождаться итоговой аттестацией с последующим вручением слушателю документа установленного образца (удостоверения о повышении квалификации, диплома о переподготовке) и по российскому законодательству не относится к АПО. В таком контексте использование рассматриваемого индикатора не исключает полностью возможность некоторого пересечения с более общими понятиями - «непрерывное образование взрослых», «дополнительное образование взрослых» и др.

\section{РЕЗУ $Б$ АТТЫ}

Аанные, представленные на рис. 1 (с. 26), позволяют сделать вывод о том, что европейские страны - участницы проекта - весьма дифференцированы по показателю охвата населения АПО. Например, минимальное и максимальное для Европы значения рассматриваемого показателя различается более чем в пять раз. В числе лидеров по масштабам включенности оказались Финляндия, Норвегия, Аания, Швеция, Швейцария, Германия, Нидерланды. Последнее согласуется с мнением экспертов о том, что теория «образование в течение жизни» особого влияния достигла в странах Скандинавии (Серякова, Кравченко, 2016). Скандинавская модель дополнительного профессионального образования, как известно, характеризуется максимальной демократичностью на основе гарантированного доступа различных категорий населения к системе АПО, многообразием форм, массовостью образовательного охвата, индивидуализированным подходом к образовательным потребностям населения (Игнацкая, 2016: 41).

На противоположном полюсе расположились Венгрия, Россия, Чехия, Аитва, Польша, Израиль. Обратим внимание, что группу государств с низкой включенностью населения в дополнительное профессиональное образование составляют в основном постсоциалистические страны. Россия на общеевропейском фоне характеризуется одним из самых низких показателей охвата населения $А П О-11 \%$ респондентов, что позволяет характеризовать ситуацию с включенностью россиян в дополнительное профессиональное образование как неблагоприятную.

Полученные результаты по России согласуются с материалами других исследований. По данным авторов проекта «Исследование российского рынка онлайн-образования и образовательных технологий», доля граждан в возрасте от 25 до 64 лет, обучающихся по программам АПО, составляла в 2016 г. 8\% от возрастной когорты (Исследование ..., 2017: Электронный ресурс). Отмечается, что рынок АПО в России имеет большие перспективы развития, поскольку потребность в переподготовке и повышении квалификации работников удовлетворена лишь на 10-20\% (Озерова, Бородина, 2013). Несколько отличаются от данных ESS (2014 г.) результаты межстранового социологического исследования «Евробарометр», проведенного в России в 2015 г. Включенность в дополнительное образование отметили $33 \%$ респондентов (опрашивались россияне в возрасте 18 лет и старше) (Евробарометр ... : Электронный ресурс). 


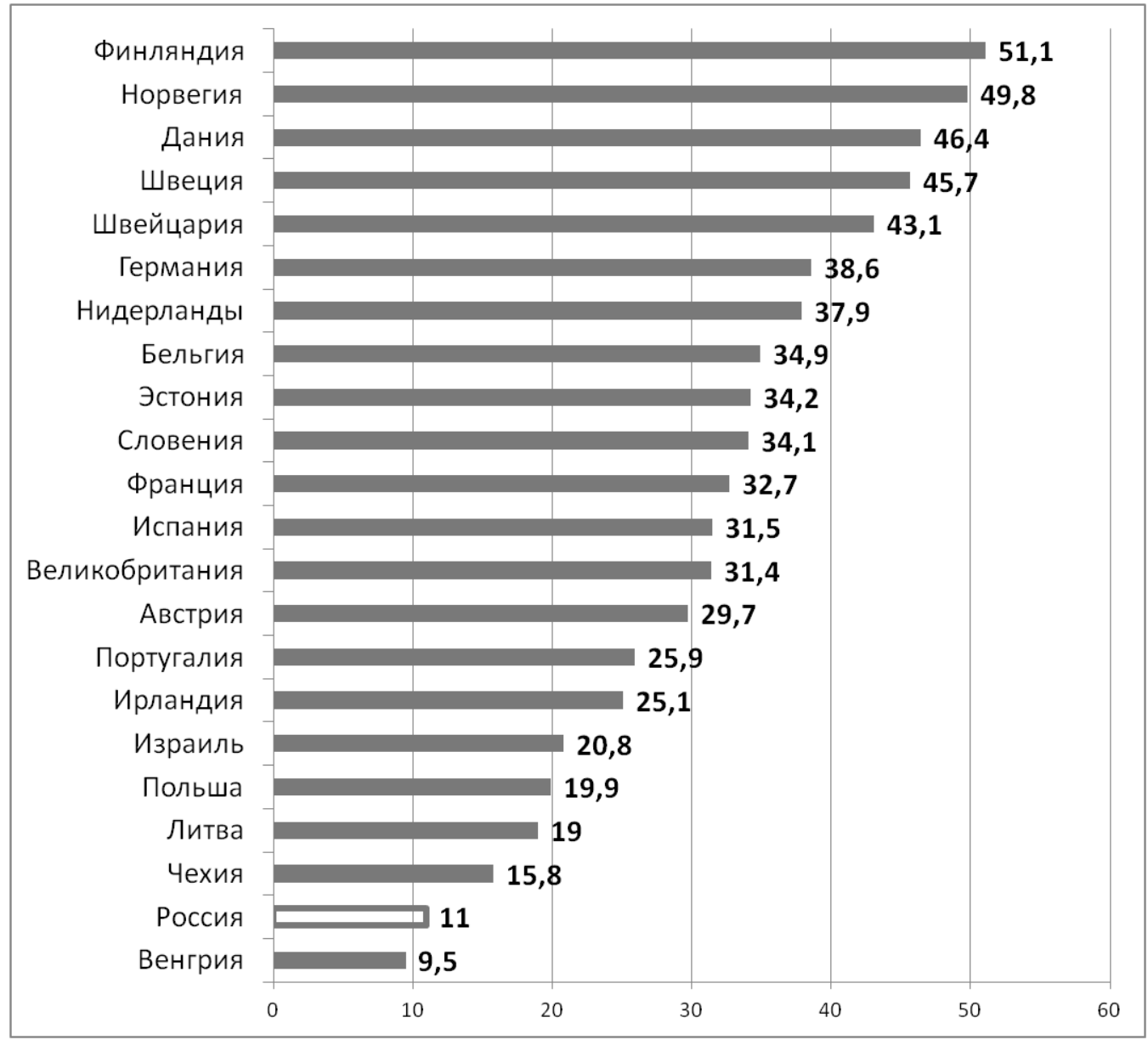

Рис. 1. Аола респондентов, посещавших в течение года какие-либо курсы, лекиии, тренинги или занятия (\% от числа опрошенных в каждой стране)

Fig. 1. The proportion of respondents attending courses, lectures, trainings or classes during the year (\% of the number of respondents in each country)

Имеющиеся различия можно объяснить использованием разных методик измерения. В рамках «Евробарометра» задавался вопрос о получении респондентом дополнительного образования без привязки усовершенствования знаний и навыков к профессиональной деятельности. Впрочем, исследователи интерпретируют этот показатель применительно к работающим россиянам как вовлеченность именно в систему АПО. В таком случае дополнительным профессиональным образованием оказалось охвачено 45\% работающих респондентов (Авраамова и др., 2016). При этом временной период, в течение которого констатировался факт получения дополнительного образования, определялся пятью годами, предшествующими опросу. Перерасчет с учетом устоявшейся в современной России практики обязательного для работников бюджетной сферы повышения квалификации применительно к взрослому населению в целом позволяет выйти на сопоставимые с ESS (2014 г.) результаты. 
Отметим, что масштабы включенности россиян в дополнительное профессиональное образование весьма устойчивы во времени. Так, по результатам ESS 2010 г. все те же $11 \%$ россиян отмечали включенность в систему АПО (Прохода, 2013: 141).

Таким образом, в России налицо противоречие между представлением о важной роли АПО и низкими показателями охвата дополнительным образованием населения. С одной стороны, в официальных документах декларируется необходимость развития системы дополнительного профессионального образования, запуска новых программ, соответствующих приоритетным направлениям технологического развития государства (Постановление Правительства ..., 2015: Электронный ресурс), подчер-

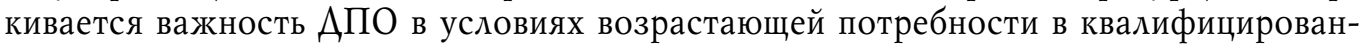
ных кадрах. На государственном уровне ставилась задача превращения АПО «в один из мощных факторов, позволяющих гражданину быть непрерывно адаптированным к изменениям в технологической и социально-экономической сферах, влияющих на ускорение структурной перестройки производства, формирование мотивации работников к высокопроизводительному и творческому труду...» (Программа развития ... , 2002: Электронный ресурс). С другой стороны, в России фиксируются одни из самых низких в Европе показателей включенности населения в АПО.

Возможны различные объяснения сложившейся ситуации. Исследование показало, что вовлеченность населения европейских стран в дополнительное профессиональное образование связана с уровнем благосостояния граждан. Результаты корреляционного анализа позволяют констатировать наличие значимой положительной

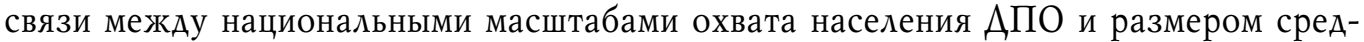
ней месячной заработной платы (в евро) в той или иной стране $(\mathrm{r}=0,728 ; \mathrm{p}<=0,001)$. В целом чем выше уровень зарплаты в стране, тем больший процент жителей констатирует включенность в дополнительное профессиональное образование. Очевидно, что население может брать на себя ту или иную часть расходов, связанных с получением АПО.

В таком контексте интересны результаты пятой волны ESS 2010 г. Тогда респондентам задавался следующий вопрос, касающийся оплаты обучения: "Сколько курсов, лекиий, тренингов оплачивал Ваш работодатель или организачия? " Аля ответа предлагалось пять вариантов от «1»- «все» до «5»- «ни одного». Источники финансирования дополнительного профессионального образования представлены на рис. 2 (с. 28) (данные по Австрии и Аитве не отображены, поскольку отсутствуют в базе данных ESS 2010 г.).

В абсолютном большинстве европейских стран обучение населения в системе $А П О$ в основном оплачивает работодатель. Особенно сильно это проявляется в Швеции (83\% респондентов от числа охваченных АПО отметили, что обучение полностью оплачивал работодатель), Аании (82\%), Франции (75,5\%), Нидерландах $(75,2 \%)$, Норвегии $(74,1 \%)$. Только в Ирландии и России доля респондентов, оплачивающих образование полностью самостоятельно (соответственно 58,3\% и 45,9\%), превышает процент опрошенных, чье образование полностью оплачивает работодатель или другая организация.

Результаты по России отчасти согласуются с данными других исследований. Так, по данным «Евробарометра» 2015 г., 44,6\% работающих россиян самостоятельно оплачивали полученное дополнительное образование. При этом чаще всего самостоятельно оплачивались программы российских университетов - 40,5\% работающих респондентов, получавших АПО, в предшествующие пять лет, коммерческие курсы - 


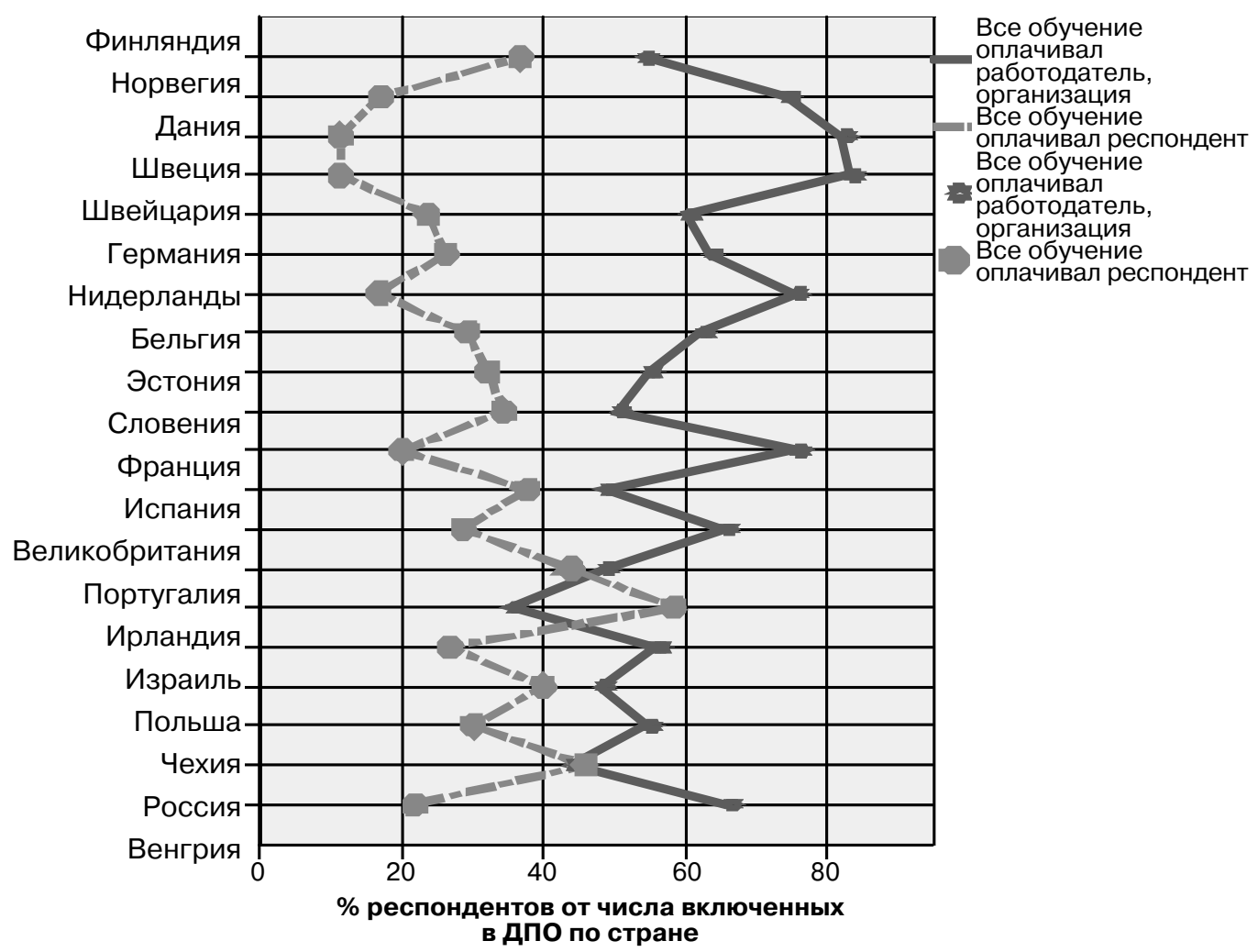

Рис. 2. Источники финансирования дополнительного профессионального образования (\% от числа опрошенных, посещавших какие-либо курсы, лекиии, тренинги или занятия)

Fig. 2. Sources of financing of additional professional education

(\% of the number of respondents attended any courses, lectures, trainings or classes)

$31,6 \%$, интернет-обучение - $15,8 \%$, дистанционное образование при университетах (российских и зарубежных) - 13\% респондентов (Авраамова и др., 2016: 21-22).

Отметим, что в европейских странах гораздо шире, чем в России, распространено обучение персонала непосредственно на предприятиях, в рамках корпоративных университетов, а не только на базе заведений высшего образования. Например, в Германии наиболее распространенной формой АПО является профильное обучение на предприятиях, важная роль отводится учебно-имитационным фирмам и учебным центрам, создаваемым при совместном участии частных фирм и государства (Векслер, 2008: 56).

Парадоксально, но в сравнительно небогатой (на общеевропейском фоне) по уровню средней заработной платы России население, охваченное АПО, гораздо чаще жителей абсолютного большинства других стран - участниц ESS самостоятельно финансирует получение дополнительного профессионального образования. Остается констатировать, что в России государство не смогло масштабно привлечь работодателей к финансированию программ АПО. При этом результаты исследований показывают, что в организациях при отсутствии существенного расширения фактической деятельности по дополнительному обучению работников работодатели сообщают о де- 
фиците компетенций у своих сотрудников. В качестве основной причины отсутствия подготовки и переподготовки персонала выступает недостаточность средств (Озерова, Бородина, 2013: 92). Можно также предположить, что некоторая часть экономически успешных отечественных работодателей, имея необходимые материальные ресурсы, не рассматривает повышение человеческого капитала работников в качестве значимого конкурентного преимущества.

$\mathrm{K}$ числу базовых тенденций развития АПО за рубежом исследователи относят рост роли государства в процессах обеспечения профессионального обучения, который выражается в их приоритетном финансировании при централизованном контроле (Игнацкая, 2016: 38). В таком контексте отметим, что по результатам исследования включенность населения в дополнительное профессиональное образование связана с уровнем экономического развития государства. Аля выявления корреляционной связи использовался показатель валового внутреннего продукта (ВВП) на душу населения по паритету покупательной способности за 2014 г. (World ... : Электронный ресурс). В целом чем больше показатель ВВП в той или иной стране, тем больше доля респондентов, посещавших в течение года курсы, лекции, тренинги и т. А. $(r=0,728$; $\mathrm{p}<=0,001)$ (рис. 3, с. 30).

На рис. 3 просматривается деление европейских стран на «богатую» и «бедную» Европу. Аевый нижний угол диаграммы условно назовем «неблагополучным»- чем ближе к нему расположена страна, тем ниже в ней масштабы включенности в $А П О$ и уровень экономического развития. В группу «аутсайдеров» по двум рассматриваемым характеристикам входят: Россия, Венгрия, Чехия, Аитва и Польша. Правый верхний угол диаграммы - «благополучный»: чем ближе к нему страна, тем более благоприятную оценку ситуации можно дать по этой стране. Наличие отдельных исключений (например, Финляндия или Ирландия) на общую картину существенно не влияет. Очевидно, что экономически развитые государства имеют возможность построить эффективную систему финансового стимулирования работников к совершенствованию компетенций и навыков в рамках АПО. Например, в Германии правительство выделяет безвозмездные дотации специалистам на период профессионального обучения. В России же, как отмечают отечественные исследователи, участие государства ограничивается прежде всего содействием переквалификации работников предпенсионного возраста и поддержкой населения старшего возраста либо финансированием повышения квалификации или переподготовкой работников силовых ведомств (Авраамова и др., 2016: 25).

\section{ЗАКАЮЧЕНИЕ}

Таким образом, проведенный анализ позволяет констатировать, что на фоне подавляющего большинства европейских стран Россия характеризуется низким уровнем включенности населения в дополнительное профессиональное образование. При этом в нашей стране среди населения, охваченного $А П О$, фиксируется один из самых больших в Европе процент респондентов, самостоятельно финансирующих получение дополнительного образования. Последнее может свидетельствовать о том, что государство не смогло масштабно привлечь работодателей к финансированию программ АПО. В целом же выявлена прямая зависимость между масштабами включенности жителей европейских стран в дополнительное профессиональное образование, с одной стороны, и уровнями благосостояния населения и экономического развития страны - с другой. 


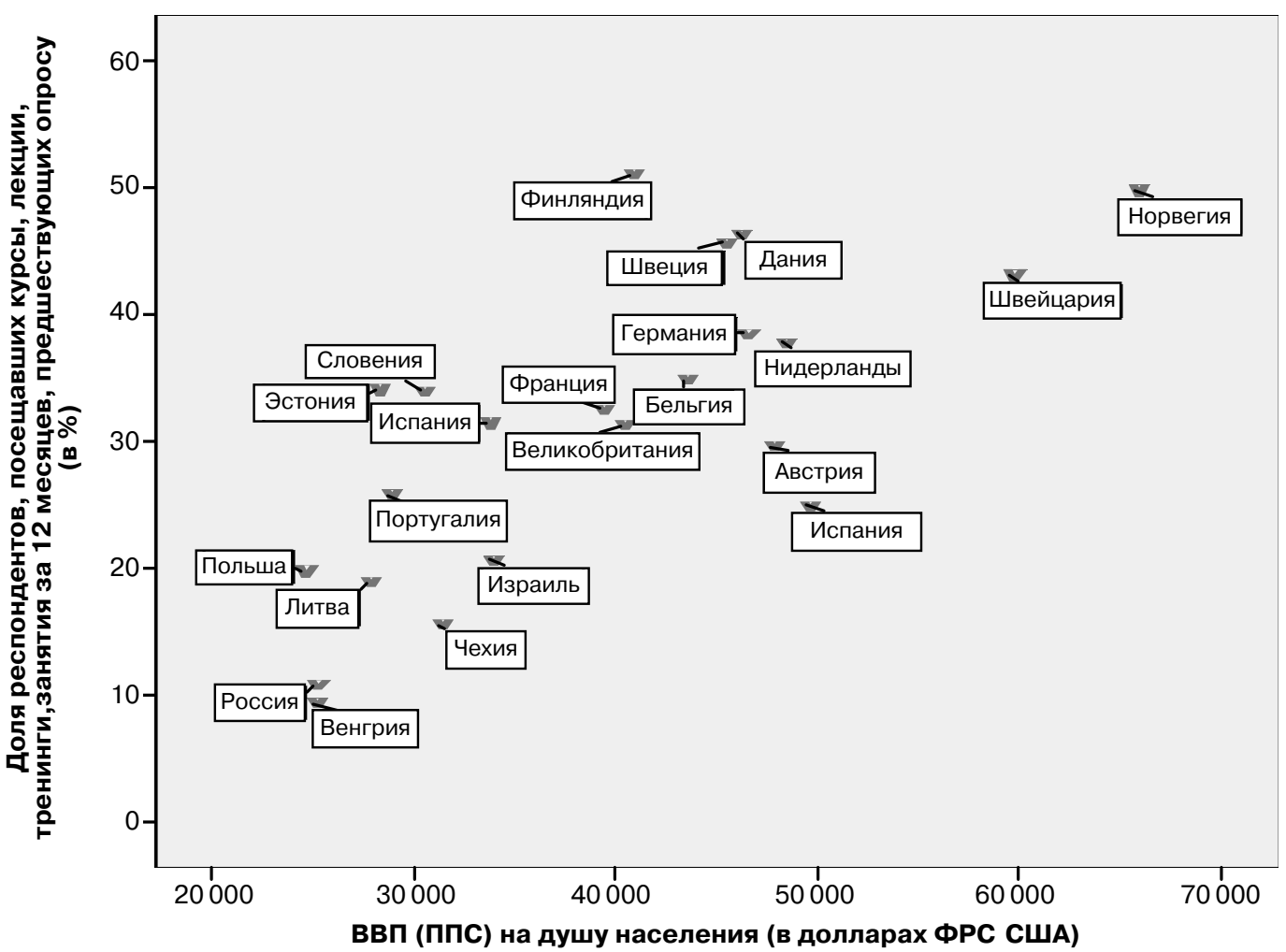

Рис. 3. Аоля респондентов, посещавших курсы, лекиии, тренинги, занятия за 12 месячев, предшествуюших опросу, в зависимости от ВВП (ППС) на душу населения

Fig. 3. Percentage of respondents attended courses, lectures, trainings, classes for 12 months preceding the poll, depending on Gross domestic product per capita

В заключение отметим, что в настоящей публикации рассматриваются лишь некоторые аспекты затрагиваемой проблематики. Представляется перспективным выявление масштабов включенности в дополнительное профессиональное образование различных социально-демографических групп в структуре населения европейских государств с последующим использованием регрессионного анализа для определения факторов и барьеров, оказывающих влияние на уровень включенности.

\section{СПИСОК АИТЕРАТУРЫ}

Федеральный закон от 29 декабря 2012 г. № 273-Ф3 «Об образовании в Российской Федерации» (2012) [Электронный ресурс] // Российская газета. Федеральный выпуск. 31 декабря. № 5976 (303). URL: https://rg.ru/2012/12/30/obrazovanie-dok.html (дата обращения: 27.06.2017).

Авраамова, Е. М., Каравай, А. В., Клячко, Т. А., Аогинов, А. М. (2016) Мониторинг дополнительного профессионального образования в России. М. : Издательский дом «Аело» РАНХиГС. 96 с.

Аналитический доклад по функционированию системы дополнительного профессионального образования в Российской Федерации в 2013 году (2013) / А. Г. Абрамов и др. М. : ФГАУ ГНИИ ИТТ «Информика». 90 с.

Аналитический доклад о реализации дополнительных профессиональных программ в Российской Федерации за 2015 год (2015) [Электронный ресурс]// Автоматизированная информа- 
ционная система сбора, анализа и представления информации о реализации дополнительного профессионального образования и профессионального обучения в Российской Федерации. URL: http://as-dpe.mon.gov.ru/files/contentfile/2/analit-doklad-2015.pdf (дата обращения: 27.06.2017).

Андреенкова, А. В. (2014) Сравнительные межстрановые исследования в социальных науках: теория, методология, практика. М. : Новый хронограф. 516 с.

Векслер, В. А. (2008) Современное состояние и тенденции развития дополнительного образования взрослых за рубежом // Вестник Костромского государственного университета им. Н. А. Некрасова. № 3. С. 55-59.

Евробарометр в России [Электронный ресурс] // Портал социологических данных РАНХиГС. URL: http://social.ranepa.ru/tsentr-sotsiologicheskikh-issledovanij-ion (дата обращения: 27.06.2017).

Игнацкая, М. А. (2016) Развитие системы дополнительного профессионального образования в сфере управления (public \& business administration) в России и за рубежом - опыт, проблемы, перспективы // Вестник РУАН. Серия Государственное и муниципальное управление. №3. C. 32-47.

Исследование российского рынка онлайн-образования и образовательных технологий (2017) [Электронный ресурс] // Russian EdTech Think Tan. URL: http://edumarket.digital (дата обращения: 27.06.2017).

Меморандум непрерывного образования Европейского Союза [Электронный ресурс]// Общество «Знание» России, 2001. URL: http://www.znanie.org/docs/memorandum.html (дата обращения: 27.06.2017).

Озерова, О. К., Бородина, А. Р. (2013) Аополнительное профессиональное образование в России. Цифры, факты, тенденции // Аккредитация в образовании. № 66. С. 92-93.

Попова, И. П. (2011) Аополнительное профессиональное образование: тенденции в реализации интеллектуально-профессионального потенциала // Содержание, формы и методы обучения в высшей школе. Вып. 11. М. : ФГАУ ФИРО. 64 с.

Прохода, В.А. (2013) Включенность в систему образования взрослого населения европейских стран // Материалы научно-практической конференции философского факультета МГУ имени М. В. Аомоносова: «Возрасты образования: социальное и личностное измерения» / под общ. ред. Е. В. Брызгалиной. М. : Центр стратегической конъюнктуры. 150 с. C. $140-142$.

Серякова, С. Б., Кравченко, В. В. (2016) Аополнительное профессиональное образование в России и странах Западной Европы: сопоставительный анализ. М. : Прометей. 164 с.

Серякова, С. Б., Кравченко, В. В. (2012) Общее и особенное в отечественном и западноевропейском дополнительном профессиональном образовании // Вестник Воронежского государственного технического университета. Т. 8. № 10-2. С. 30-35.

Программа развития дополнительного профессионального образования в Российской Федерации на 2002-2005 годы (2002) [Электронный ресурс]// Электронный Фонд правовой и нормативно-технической документации. URL: http://docs.cntd.ru/document/901856560 (дата обращения 27.06.2017).

Постановление Правительства РФ от 23 мая 2015 г. № 497 «О Федеральной целевой программе развития образования на 2016-2020 годы» [Электронный ресурс]// Министерство образования и науки Российской Федерации. URL: http://минобрнауки.рф/документы/5930/ файл/4787/FCPRO_na_2016-2020_gody.pdf (дата обращения: 27.06.2017).

World Development Indicators. GDP based on purchasing-power-parity (PPP) per capita 2014 [Электронный ресурс] // The World Bank. URL: http://databank.worldbank.org/data/reports. aspx?source=2\&series=NY.GDP.PCAP.PP.CD (дата обращения: 27.06.2017). 


\section{THE INVOLVEMENT OF THE RESIDENTS OF EUROPEAN STATES \\ IN THE SUPPLEMENTARY VOCATIONAL EDUCATION \\ V. A. PROKHODA \\ LOMONOSOV MOSCOW STATE UNIVERSITY; \\ FINANCIAL UNIVERSITY UNDER THE GOVERNMENT OF THE RUSSIAN FEDERATION}

The author analyzes the results of the comparative cross-country sociological survey «European Social Research» (2014). The article elicits the scale of the involvement of European countries' population in supplementary vocational education. European countries differ very much in terms of the population coverage of additional professional education. Finland, Denmark, Norway, Sweden, Switzerland, Germany, and the Netherlands turned up among the leaders from the position of involvement.

In modern Russia there is a contradiction between the declared need for the development of the supplementary vocational education system and the extremely low rate of the population's involvement in the supplementary vocational education by European standards. It is noted that overall results in Russia generally correlate with the data of other sociological studies. Based on a comparative analysis of data from 2010 and 2014, it is stated that the rate of Russians' involvement in supplementary vocational education has been stable over time. The article also considers the sources of funding of the supplementary vocational education. In the overwhelming majority of European countries the supplementary vocational education of the population is mainly paid for by the employer. This is especially evident in Sweden, Denmark, France, the Netherlands and Norway.

It is noted that the population of Russia involved in supplementary vocational education pay for education themselves much more frequently than the residents of the absolute majority of other European countries. It is concluded that the Russian state has not been able to involve employers in the financing of the supplementary vocational education programs on a large scale. It was revealed that the extent of the involvement of European residents in the supplementary vocational education is related to the level of the welfare of the population, as well as to the level of economic development of the state. It is concluded that the higher the level of the average monthly salary in the country, the greater the percentage of residents stating the involvement in the supplementary vocational education.

Keywords: supplementary vocational education; supplementary education; continuing education; adult education; life-long learning; involvement in education; population of European countries; Europe

\section{REFERENCES}

Federal'nyi zakon ot 29 dekabria 2012 g. № 273-FZ «Ob obrazovanii v Rossiiskoi Federatsii» (2012). Rossiiskaia gazeta. Federal' nyi vypusk. 31 December, no. 5976 (303) [online] Available at: https://rg.ru/2012/12/30/obrazovanie-dok.html (access date: 27.06.2017). (In Russ.).

Avraamova, E. M., Karavai, A. V., Kliachko, T. L. and Loginov, D. M. (2016) Monitoring dopolnitel' nogo professional' nogo obrazovaniia v Rossii. Moscow, Izdatel'skii dom «Delo» RANKhiGS. 96 p. (In Russ.).

Analiticheskii doklad po funktsionirovaniiu sistemy dopolnitel' nogo professional' nogo obrazovaniia v Rossiiskoi Federatsii v 2013 godu (2013) / Abramov A. G. et al. Moscow, FGAU GNII ITT «Informika». 90 p. (In Russ.).

Analiticheskii doklad o realizatsii dopolnitel'nykh professional'nykh programm v Rossiiskoi Federatsii za 2015 god (2015). Avtomatizirovannaia informatsionnaia sistema sbora, analiza i predstavleniia informatsii o realizatsii dopolnitel'nogo professional' nogo obrazovaniia $i$ professional'nogo obucheniia v Rossiiskoi Federatsii [online] Available at: http://as-dpe.mon.gov.ru/files/ contentfile/2/analit-doklad-2015.pdf (access date: 27.06.2017). (In Russ.).

Andreenkova, A. V. (2014) Sravnitel'nye mezhstranovye issledovaniia v sotsial'nykb naukakb: teoriia, metodologiia, praktika. Moscow, Novyi khronograf. 516 p. (In Russ.).

Veksler, V. A. (2008) Sovremennoe sostoianie i tendentsii razvitiia dopolnitel'nogo obrazovaniia vzroslykh za rubezhom. Vestnik Kostromskogo gosudarstvennogo universiteta im. N. A. Nekrasova, no. 3, pp. 55-59. (In Russ.). 
Evrobarometr v Rossii. Portal sotsiologicheskikb dannykb RANKhiGS [online] Available at: http://social.ranepa.ru/tsentr-sotsiologicheskikh-issledovanij-ion (access date: 27.06.2017). (In Russ.).

Ignatskaia, M. A. (2016) Razvitie sistemy dopolnitel'nogo professional'nogo obrazovaniia v sfere upravleniia (public \& business administration) v Rossii i za rubezhom - opyt, problemy, perspektivy. Vestnik RUDN. Seriia Gosudarstvennoe i munitsipal' noe upravlenie, no. 3, pp. 32-47. (In Russ.).

Issledovanie rossiiskogo rynka onlain-obrazovaniia i obrazovatel'nykh tekhnologii (2017). Russian EdTech Think Tan [online] Available at: http://edumarket.digital (access date: 27.06.2017). (In Russ.).

Memorandum nepreryvnogo obrazovaniia Evropeiskogo Soiuza. Obshchestvo «Znanie» Rossii, 2001 [online] Available at: http://www.znanie.org/docs/memorandum.html (access date: 27.06.2017). (In Russ.).

Ozerova, O. K. and Borodina, D. R. (2013) Dopolnitel'noe professional'noe obrazovanie v Rossii. Tsifry, fakty, tendentsii. Akkreditatsiia v obrazovanii, no. 66, pp. 92-93. (In Russ.).

Popova, I. P. (2011) Dopolnitel'noe professional'noe obrazovanie: tendentsii v realizatsii intellektual'no-professional'nogo potentsiala. In: Soderzhanie, formy $i$ metody obucheniia $v$ vysshei shkole. Vol. 11. Moscow, FGAU FIRO. 64 p. (In Russ.).

Prokhoda, V. A. (2013) Vkliuchennost' v sistemu obrazovaniia vzroslogo naseleniia evropeiskikh stran. In: Materialy nauchno-prakticheskoi konferentsii filosofskogo fakul' teta MGU imeni M. V. Lomonosova: "Vozrasty obrazovaniia: sotsial' noe i lichnostnoe izmereniia» / ed. by E. V. Bryzgalina. Moscow, Tsentr strategicheskoi kon»iunktury. 150 p. Pp. 140-142. (In Russ.).

Seriakova, S. B. and Kravchenko, V. V. (2016) Dopolnitel'noe professional' noe obrazovanie $v$ Rossii i stranakb Zapadnoi Evropy: sopostavitel' nyi analiz. Moscow, Prometei. 164 p. (In Russ.).

Seriakova, S. B. and Kravchenko, V. V. (2012) Obshchee i osobennoe v otechestvennom i zapadnoevropeiskom dopolnitel'nom professional'nom obrazovanii. Vestnik Voronezhskogo gosudarstvennogo tekbnicheskogo universiteta, vol. 8, no. 10-2, pp. 30-35. (In Russ.).

Programma razvitiia dopolnitel'nogo professional'nogo obrazovaniia v Rossiiskoi Federatsii na 2002-2005 gody (2002). Elektronnyi Fond pravovoi $i$ normativno-tekbnicheskoi dokumentatsii [online] Available at: http://docs.cntd.ru/document/901856560 (access date 27.06.2017). (In Russ.).

Postanovlenie Pravitel'stva RF ot 23 maia 2015 g. № 497 «O Federal'noi tselevoi programme razvitiia obrazovaniia na 2016-2020 gody». Ministerstvo obrazovaniia i nauki Rossiiskoi Federatsii [online] Available at: http://minobrnauki.rf/dokumenty/5930/fail/4787/FCPRO_na_20162020_gody.pdf (access date: 27.06.2017). (In Russ.).

World Development Indicators. GDP based on purchasing-power-parity (PPP) per capita 2014. The World Bank [online] Available at: http://databank.worldbank.org/data/reports.aspx?source= 2\&series=NY.GDP.PCAP.PP.CD (access date: 27.06 .2017 ).

Submission date: 31.08.2017.

Прохода Владимир Анатольевич - кандидат социологических наук, старший научный сотрудник кафедры философии образования философского факультета Московского государственного университета им. М. В. Аомоносова; доцент департамента социологии Финансового университета при Правительстве Российской Федерации. Адрес: 119234, Россия, г. Москва, енинские горы, МГУ, учебно-научный корпус «Шуваловский». Тел.: +7 (495) 939-20-08. Эл. аАpec:prochoda@mail.ru

Prokhoda Vladimir Anatolievich, Candidate of Sociology, Senior Research Fellow, Department of Philosophy of Education, Faculty of Philosophy, Lomonosov Moscow State University; Associate Professor, Department of Sociology, Financial University under the Government of the Russian Federation. Postal address: educational and scientific building «Shuvalovsky», MSU, Leninskie Gory, Moscow, Russian Federation 119234. Tel.: +7 (495) 939-20-08. E-mail: prochoda@mail.ru 